\title{
FORMULASI GEL DAN UJI EFEKTIVITAS EKSTRAK ETANOL DAUN MENIRAN (Phyllanthus niruri L.) TERHADAP PENYEMBUHAN LUKA SAYAT PADA KELINCI JANTAN (Oryctolagus cuniculus)
}

\author{
Gel Formulation and Effectiviness Test of Ethanol Extract of Small Meniran Leaves \\ (Phyllanthus niruri L.) toward Recorvery of Incision Wound to Male Rabbit (Orygtolagus \\ cuniculus)
}

\author{
Wahyuni, Ahmad Irsyad Aliah, Erni Semboh \\ Universitas Megarezky Makassar \\ E-mail Korespondensi : unhyhasan@gmail.com \\ ahmadirsyadaliah@universitasmegarezky.ac.id
}

\begin{abstract}
ABSTRAK
Telah dilakukan penelitian tentang Formulasi Gel Dan Uji Efektivitas Ekstrak Etanol Daun Meniran (Phyllanthus niruri L.) Terhadap Penyembuhan Luka Insisi Pada Kelinci Jantan (Orygtolagus cuniculus). Daun meniran (Phyllanthus niruri L.) memiliki kandungan saponin, flavonoid. Daun meniran (Phyllanthus niruri L.) diekstraksi dengan metode meserasi menggunakan cairan penyari etanol $70 \%$. Perlakuan dibagi 5 kelompok yaitu kontrol negatif (Gel basis tanpa ekstrak) dan control positif (Povidone lodine), konsentrasi 3\%, konsentrasi 6\%, dan konsentrasi 9\%. Gel dioileskan pada kulit kelinci (sebanyak 3-4 kali sehari ). Uji efek penyembuhan luka sayat pada kulit kelinci yang telah diberikan perlakuan sayat pada kulit untuk semua sediaan gel ekstrak etanol daun meniran (Phyllanthus niruri L.) 3\%, 6\%, 9\% beserta kontrol negatif dan kontrol positif . Dari hasil uji statistik Rancangan Acak Lengkap (RAL) dapat disimpulkan bahwa sediaan gel ekstrak Daun meniran (Phyllanthus niruri L.) pada konsentrasi 3\%, 6\%, dan 9\% memberikan efek penyembuhan luka sayat yang baik. Semakin tinggi konsentrasi sediaan gel maka semakin cepat penyembuhan luka sayat.
\end{abstract}

Kata kunci : Gel, ekstrak daun meniran, luka sayat, kelinci jantan (Oryctolagus cuniculus)

\section{ABSTRACT}

It has been done research about gel formulation and effectiveness test of ethanol extract of small meniran leaves (Phyllanthus niruri L.) toward recovery of incision to male rabbit (Oryctolagus cuniculus). Small meniran leaves (Phyllanthus niruri L.) have saponin and flavonoid content. It was extracted by maceration method using $70 \%$ ethanol solvent. Treatment was divided into 5 groups such as negative control (gelling agent without extract), positive control (Povidone lodine), 3\% concentration, 6\% concentration, and 9\% concentration. Gel was smeared to skin of rabbit (2-3 times a day). Effectiveness test of incision recovery to skin of rabbit had been given treatment incision wound to all gel supply of ethanol extract of small meniran leaves (Phyllanthus niruri L.) as many as 3\%, 6\% and 9\% with negative and positive controls. Based on complete randomized design, it can be concluded that $3 \%, 6 \%$ and $9 \%$ gel supply of ethanol extract of small meniran leaves (Phyllanthus niruri L.) give good effect of incision recovery. The highest concentration of gel supply, the faster recovery of incision. It is expected to do further research about combination other plants extract that have the same benefit to wound recovery.

Keywords : Gel, small meniran leaves, incision wound, Male Rabbit (Orygtolagus cuniculus)

\section{PENDAHULUAN}

Luka adalah rusak atau hilangnya jaringan tubuh yang terjadi karena adanya suatu faktor yang menganggu sistem perlindungan tubuh. Faktor tersebut seperti trauma, perubahan suhu, Zat kimia, ledakan sengatan listrik, atau gigitan hewan. Salah satu contoh luka terbuka adalah insisi/luka sayat dimana terdapat robekan linier pada kulit dan jaringan di bawahnya.

Luka sayat adalah luka yang terjadi karena teriris oleh instrumen yang tajam. Misalnya terjadi akibat pembedahan. Ciricirinya yaitu luka terbuka, nyeri panjang luka lebih besar daripada dalamnya luka.
Salah satu tumbuhan obat yang digunakan sebagai obat tradisional adalah daun meniran (Phylanthus niruri L.) yang bisa digunakan untuk mempercepat penyembuhan luka. Hampir seluruh bagian dari tanaman ini dapat dimanfaatkan. Tanaman meniran (Phylanthus niruri L.) pada masyarakat umumnya digunakan untuk memperbaiki sistem imun alami mempunyai kandungan mampu merangsang aktivitas imuno modulator yang terjadi didalam tubuh.

Umumnya sediaan obat luka disiapkan dalam bentuk setengah padat seperti gel, salep, dan krim jadi pilihan untuk penyembuhan yang lebih baik karena 
memungkinkan waktu kontak obat yang lebih panjang dan melindungi luka dari kontaminasi luar. Bentuk sediaan ini lebih digunakan dan penyebarannya di kulit lebih cepat, dan gel mempunyai sifat yang menyejukkan, melembabkan, mudah berpenetrasi pada kulit sehingga memberikan efek penyembuhannya. Sediaan gel dapat melindungi kulit dari dehidrasi yang berlebihan. Formulasi dan pemilihan basis yang tepat pada pembuatan sediaan gel akan mempengaruhi jumlah dan kecepatan Zat aktif yang akan diabsorbsi secara ideal, basis dan pembawa harus mudah dipakai pada kulit dari dehidrasi yang berlebihan.

Tujuan penelitian ini adalah untuk mengetahui ekstrak etanol meniran (Phyllanthus niruri L.) untuk penyembuhan luka sayat dalam bentuk sediaan gel terhadap kelinci (Oryctolagus cunuculus). Pada penelitian ini menggunakan daun meniran (Phyllanthus niruri L.) yang memiliki kandungan flavonoid, saponin dan filantin. Daun meniran (Phyllanthus niruri L.) diekstraksi dengan metode meserasi menggunakan cairan penyari etanol $70 \%$. Pada penelitian ini akan membuat formulasi sediaan gel dengan 3 konsntrasi yaitu konsentrasi F1 3 \%, F2 6\% Dan F3 $9 \%$. Pada penelitian ini terlebih dahulu dilakukan pembuatan basis gel dengan menggunakan HPMC (Hydroxyprofyl methyl cellulose). HPMC di kembangkan terlebih dahulu dengan air panas pada suhu $80^{\circ} \mathrm{C}$ kemudian didiamkan selama 24 jam untuk menghilangkan gelembung yang terdapat pada basis gel. Selanjutnya dibuat pembuatan gel, diambil basis yang telah dibuat dimasukkan kedalam lumpang, kemudian ditimbang natrium benzoat sebanyak 0,5 gram lalu dimasukkan kedalam lumpang kemudian ditambahkan trietanolamin di aduk hingga homogen. Ekstrak etanol meniran (Phylanthus niruri L.) dicampur dengan gliserin setelah itu langsung di campur dengan basis. Selanjutnya pengujian efek penyembuhan luka sayat pada kelinci (Orygtolagus cuniculus). Penelitian ini dibagi menjadi 5 kelompok yaitu kontrol negatif (Gel basis tanpa ekstrak) dan kontrol positif (Povidone lodine), konsentrasi $3 \%$, konsentrasi $6 \%$, dan konsentrasi $9 \%$. Sediaan gel dioleskan pada kulit kelinci (sebanyak 3-4 kali sehari).

\section{METODE PENELITIAN \\ Desain, Tempat dan Waktu}

Jenis penelitian yang dilakukan adalah metode eksperimental untuk menguji ekstrak daun meniram (Phyllanthus urinaria L.) sebagai obat luka sayat pada kelinci (Oryctolagus cuniculus).

Penelitian ini dilakukan di

Laboratorium Farmasetika Universitas Megarezky Makassar pada bulan JuliSeptember 2020

\section{Bahan dan alat}

Bahan-bahan yang digunakan dalam penelitian ini adalah air suling, ekstrak daun meniran, etanol $70 \%$. Alat-alat yang digunakan dalam penelitian ini antara lain cawan porselin (Iwaki Pirex ${ }^{\circledR}$ ), eksikator (Normax), gelas kimia (Iwaki Pirex ${ }^{\circledR}$ ), gelas ukur (Iwaki Pirex ${ }^{\circledR}$ ), kandang hewan, labu ukur (Iwaki Pirex ${ }^{\circledR}$ ), lumpang $(R R C)$, mangkok maserasi, pipet tetes (Pudak), rotavapor (Scilogex), stopwatch, timbangan analitik $\left(\right.$ Ohaus $\left.^{\circledR}\right)$, dan wadah maserasi (toples).

\section{Langkah-langkah penelitian}

\section{Pengambilan dan pengelolaan sampel}

Pengambilan sampel daun meniran (Phylanthus niruri L.) yang digunakan diperoleh dari Makassar, Sulawesi Selatan. Pengambilan sampel dilakukan di pagi hari dengan cara daun meniran (Phyllanthus niruri L.) dipetik dan dipisahkan dari batang, bunga dan buah.

Pengolahan Sampel daun meniran (Phyllanthus niruri L.) di cuci bersih dengan air mengalir, dikeringkan dan ditimbang hingga terbentuk simplisia kering. Sampel diekstraksi secara maserasi menggunakan etanol disimpan selama 24 jam pada suhu kamar. Setelah itu disaring kemudian filtrat dipekatkan denga rotary evaporator dan dikeringkan menggunakan freeZe dryer.

2. Pembuatan Bahan Penelitian
a. Pembuatan Gel dan Formulasi Sediaan Gel dapat dilihat di Tabel 1 pada lampiran.
b. Pembuatan basis gel
Sediaan gel dengan HPMC dengan cara HPMC di kembangkan terlebih 
dahulu dengan air panas pada suhu $80^{\circ} \mathrm{C}$ didiamkan selama 24 jam untuk menghilangkan gelembung yang terdapat pada basis gel.

c. Pembuatan gel

Diambil basis yang telah dibuat dimasukkan kedalam lumpang, kemudian ditimbang natrium benzoat sebanyak 0,5 gram lalu dimasukkan kedalam lumpang kemudian ditambahkan propilenglikol di aduk hingga homogen. Ekstrak etanol meniran (Phylanthus niruri L.) dicampur dengan gliserin Setelah itu langsung di campur dengan basis.

\section{Pengujian efek penyembuhan luka sayat secara in vivo \\ Kelinci diadaptasi selama 7 hari} dalam kondisi ruangan dengan tetap diberi makanan dan minuman kelinci (Orygtolagus cuniculus) yang digunakan adalah kelinci jantan (Orygtolagus cuniculus) sehat dan memiliki berat badan antara 1,5 sampai $2 \mathrm{~kg}$. Penelitian ini terbagi menjadi 5 kelompok dan setiap kelompok menggunakan hewan uji kelinci (Orygtolagus cuniculus) sebanyak 5 ekor, hewan uji diberikan perlakuan sebagai berikut:

- Kelompok: Luka dioleskan sediaan gel yang mengandung ekstrak etanol daun meniram (Phyllanthus nirunary L.) $3 \%$

- Kelompok II: Luka dioleskan sediaan gel yang mengandung ekstrak etanol daun meniran (Phyllanthus niruri L.) $6 \%$

- Kelompok III: Luka dioleskan sediaan gel yang mengandung ekstrak etanol daun meniran (Phyllanthus niruri L.) $9 \%$

- Kelompok IV : Luka dioleskan kontrol positif ( Povidone lodine 10\%)

- Kelompok V: Luka dioleskan kontrol negatif ( basis)

\section{Pengumpulan dan Analisis Data}

Pengumpulan dan analisis data dilakukan berdasarkan pengukuran panjang luka serta waktu yang diperlukan hingga luka pada hewan coba sembuh dengan menggunakan formulasi sediaan gel yang mengandung ekstrak etanol daun meniran (Phyllanthus niruri L.) pada konsentrasi berbeda.

\section{HASIL}

Pada penelitian ini dilakukan pengukuran panjang luka sayat pada kelinci dengan menggunakan alat ukur mistar setiap hari selama perlakuan yaitu selama 14 hari dan pada kelompok HPMC mengalami penyembuhan luka yang agak lama dibandingkan dengan kelompok yang lain. Dan yang paling cepat sembuh yaitu kelompok ekstrak daun meniran (Phyllanthus niruri) 9\%

\section{PEMBAHASAN}

Penelitian ini berujuan untuk mengetahui efektivitas sediaan gel ekstrak daun meniran (Phyllathus niruri L.) terhadap penyembuh luka insisi kelinci (Oryctolagus cuniculus), agar masyarakat mengetahui bahwa daun meniran (Phyllathus niruri L.) tersebut mempunyai efektivitas dalam penyembuhan luka sayat apabila di formulasikan dalam bentuk sediaan gel luka.

Pada penelitian ini zat aktif yang digunakan adalah ekstrak daun meniran (Phyllathus niruri L.) dimana ekstrak daun meniran (Phyllathus niruri L.) tersebut digunakan sebagai penyembuh luka karena mengandung flavonoid dan saponin di dalamnya dimana berfungsi sebagai antioksidan namun juga memiliki manfaat melindungi struktur sel, anti-inflamasi. Flavonoi, saponin merupakan senyawa yang mudah larut polar dan nonpolar. Dalam penelitian ini simplisia kering di ekstraksi menggunakan pelarut semi polar yaitu etanol $70 \%$ dengan kandungan tersebut maka dibuatlah menjadi suatu sediaan, salah satunya adalah sediaan gel.

Ekstrak daun meniran (Phyllathus niruri L.) diperoleh dengan cara mengekstraksi $500 \mathrm{~kg}$ serbuk daun meniran (Phyllathus niruri L.)dengan metode maserasi, menggunakan pelarut etanol $70 \%$ dan dibiarkan selama 24 jam sambil sesekali-sekali diaduk. Rendaman disaring dan ampas direndam kembali dengan pelarut yang sama. Hal ini dilakukan selama 3 hari. Filtrat hasil maserasi ditampung dalam mangkok kaca dan kemudian dipekatkan menggunakan evaporator sehingga diperoleh ekstrak kental daun meniran (Phyllathus niruri L.) sebanyak $371 \mathrm{gr}$. 
Gel merupakan suatu sediaan semipadat yang jernih, tembus cahaya dan mengandung zat aktif, merupakan disperse koloid mempunyai kekuatan yang disebabkan oleh karingan yang saling berkaitan pada fase terdispersi membentuk semi padat jika di biarkan dan menjadi cair pada pendispersi. Sediaan gel ini dibuat dengan menggunakan zat tambahan antara lain HPMC yang berfungsi sebagai basis gel. Pengawet golongan benzoat yang berfungsi sebagai pengawet karena sediaan gel memiliki kandungan air tinggi yang dapat menyebabkan terjadinya kontaminasi mikroba. Propilen glikol $\left(\mathrm{C}_{3} \mathrm{H}_{8} \mathrm{O}_{2}\right)$ berfungsi sebagai humektan. Gliserin berfungsi sebagai emolien. Dan air suling berfungsi sebagai pelarut untuk sediaan.

Pembuatan gel ini dibuat sebanyak empat sediaan yang terdiri dari kontrol yang dibuat tanpa menggunakan ekstrak daun meniran (Phyllathus niruri L.) dan tiga sediaan lainnya dibuat dengan zat aktif daun meniran (Phyllathus niruri L.) dengan konsentrasi yang berbeda yaitu $3 \%, 6 \%$, dan $9 \%$ dengan menggunakan zat tambahan yang sama.

Pembuatan sediaan gel pada penelitian ini dilakukan dengan cara HPMC sebanyak $1 \mathrm{~g}$ dimasukkan kedalam lumpang kemudian dimasukkan air panas sedikit demi sedikit sambil digerus searah jarum jam dengan kecepatan yang konstan hingga membentuk basis gel yang baik kemudian masukkan ekstrak daun meniran (Phyllathus niruri L.) dengan konsentrasi $3 \%$ sambil digerus hingga homogen, dimasukkan natrium benzoat kemudian digerus hingga homogen ditambahkan propilenglikol dan gliserin sambil terus digerus sampai homogen. Gel yang terbentuk dimasukkan kedalam wadah yang dibutuhkan. Pembuatan gel ekstrak daun meniran (Phyllathus niruri L.) dengan konsentrasi $6 \%$ dan $9 \%$ dibuat dengan cara seperti konsentrasi $3 \%$, dimana didispersikan HPMC dengan air panas sedikit demi sedikit digerus searah jarum jam kemudian ditambahkan propilenglikol dan gliserin sambil terus digerus sampai homogen kemudian gel yang terbentuk dimasukkan kedalam wadah yang dibutuhkan.

Gel diuji penyembuhan luka pada hewan coba kelinci (Orygtolagus cuniculus) dan memberikan gel dengan cara di oleskan pada daearah punggung 3 kali sehari, setelah pemberian gel diamati perubahan yang terjadi dan di ukur panjang lukanya.

Pemberian sediaan gel yang terdiri dari control konsentrasi 3\%,6\%, dan $9 \%$ di ujikan pada kelinci (Orygtolagus cuniculus) dengan cara mengoleskan gel pada kelinci (Orygtolagus cuniculus).

Rata-rata panjang luka sayat yang terdapat pada kelinci selama 14 hari perlakuan dengan menggunakan HPMC (kontrol negatif) yaitu, hari pertama $3 \mathrm{~cm}$, hari kedua $3 \mathrm{~cm}$, hari ketiga $2,97 \mathrm{~cm}$, hari keempat $2,57 \mathrm{~cm}$, hari kelima $2,4 \mathrm{~cm}$, hari keenam $2,1 \mathrm{~cm}$, hari ketujuh $1,87 \mathrm{~cm}$, hari kedelapan $1,7 \mathrm{~cm}$, hari kesembilan 1,37 $\mathrm{cm}$, hari ke sepuluh $1,13 \mathrm{~cm}$, hari kesebelas $0,77 \mathrm{~cm}$, hari kedua belas 0,57 $\mathrm{cm}$, hari ketiga belas $0,43 \mathrm{~cm}$, dan hari keempat belas 0,26 . Luka dinyatakan belum sembuh.

Rata-rata panjang luka sayat yang terdapat pada kelinci selama 14 hari perlakuan dengan menggunakan Povidone lodine $10 \%$ (kontrol positif) yaitu, hari pertama $3 \mathrm{~cm}$, hari kedua $3 \mathrm{~cm}$, hari ketiga $2,67 \mathrm{~cm}$, hari keempat $2,5 \mathrm{~cm}$, hari kelima $2,33 \mathrm{~cm}$, hari keenam $1,9 \mathrm{~cm}$, hari ketujuh $1,63 \mathrm{~cm}$, hari kedelapan $1,33 \mathrm{~cm}$, hari kesembilan $0,7 \mathrm{~cm}$, hari ke sepuluh 0,53 $\mathrm{cm}$, hari kesebelas $0,2 \mathrm{~cm}$, hari kedua belas $0,03 \mathrm{~cm}$, hari ketiga belas $0 \mathrm{~cm}$, dan hari keempat belas $0 \mathrm{~cm}$. Luka dinyatakan sembuh.

Rata-rata panjang luka sayat yang terdapat pada kelinci selama 14 hari perlakuan dengan menggunakan gel ekstrak etanol daun meniran (Phyllanthus niruri L.) $3 \%$ yaitu, hari pertama $3 \mathrm{~cm}$, hari kedua $3 \mathrm{~cm}$, hari ketiga $2,83 \mathrm{~cm}$, hari keempat 2,57, hari kelima $2,27 \mathrm{~cm}$, hari keenam 1,97 cm, hari ketujuh $1,73 \mathrm{~cm}$, hari kedelapan $1,5 \mathrm{~cm}$, hari kesembilan 1,23 $\mathrm{cm}$, hari ke sepuluh $0,9 \mathrm{~cm}$, hari kesebelas $0,6 \mathrm{~cm}$, hari kedua belas $0,37 \mathrm{~cm}$, hari ketiga belas $1,6 \mathrm{~cm}$, dan hari keempat belas $0 \mathrm{~cm}$. Luka dinyatakan sembuh.

Rata-rata panjang luka sayat yang terdapat pada kelinci selama 14 hari perlakuan dengan menggunakan gel ekstrak etanol daun meniran (Phyllanthus niruri L.) $6 \%$ yaitu, hari pertama $3 \mathrm{~cm}$, hari kedua $3 \mathrm{~cm}$, hari ketiga $2,63 \mathrm{~cm}$, hari keempat 2,4, hari kelima $2,13 \mathrm{~cm}$, hari keenam $1,8 \mathrm{~cm}$, hari ketujuh $1,47 \mathrm{~cm}$, hari kedelapan $1,23 \mathrm{~cm}$, hari kesembilan 0,7 $\mathrm{cm}$, hari ke sepuluh $0,4 \mathrm{~cm}$, hari kesebelas $0,33 \mathrm{~cm}$, hari keduabelas $0,13 \mathrm{~cm}$, hari 
ketigabelas $0,07 \mathrm{~cm}$, dan hari keempatbelas $0 \mathrm{~cm}$. Luka dinyatakan sembuh.

Rata-rata panjang luka sayat yang terdapat pada kelinci selama 14 hari perlakuan dengan menggunakan gel ekstrak etanol daun meniran (Phyllanthus niruri L.) $9 \%$ yaitu, hari pertama $3 \mathrm{~cm}$, hari kedua $2,7 \mathrm{~cm}$, hari ketiga $2,47 \mathrm{~cm}$, hari keempat $2,17 \mathrm{~cm}$, hari kelima $2 \mathrm{~cm}$, hari keenam $1,7 \mathrm{~cm}$, hari ketujuh $1,43 \mathrm{~cm}$, hari kedelapan $1,1 \mathrm{~cm}$, hari kesembilan $0,7 \mathrm{~cm}$, hari ke sepuluh $0,27 \mathrm{~cm}$, hari kesebelas $0,17 \mathrm{~cm}$, hari kedua belas $0,03 \mathrm{~cm}$, hari ketiga belas $0 \mathrm{~cm}$, dan hari keempat belas $0 \mathrm{~cm}$. Luka dinyatakan sembuh.

Dari kelima kelompok perlakuan yang paling efektif dalam menyembuhkan luka sayat yaitu kelompok kontrol positif, yang kedua yaitu gel ekstrak etanol daun meniran 9\% (Phyllanthus niruri L.), yang ketiga yaitu gel ekstrak etanol daun meniran 6\% (Phyllanthus niruri L.), yang keempat yaitu gel ekstrak etanol daun meniran 3\% (Phyllanthus niruri L.), dan yang paling lambat menyembuhkan luka sayat yaitu kontrol negatif. Dapat disimpulkan bahwa semakin tinggi konsentrasi sediaan gel ekstrak etanol daun meniran (Phyllanthus niruri L.) maka semakin cepat penyembuhan luka sayat pada kelinci. Dan semakin rendah konsentrasi sediaan gel ekstrak etanol daun meniran (Phyllanthus niruri L.) maka semakin lambat proses penyembuhan luka sayat pada kelinci.

\section{KESIMPULAN}

Berdasarkan hasil penelitian yang telah dilaksanakan, maka dapat disimpulkan bahwa pada sediaan gel ekstrak daun meniran (Phyllanthus niruri L.) sebagai penyembuh luka insisi konsentrasi $3 \%, 6 \%$, dan $9 \%$ dapat digunakan untuk pemakaian topikal penyembuh luka insisi.

\section{Saran}

Dilakukan penelitian lanjutan dengan kombinasi ekstrak tanaman lain yang berkhasiat sama sebagai penyembuh luka.

\section{UCAPAN TERIMA KASIH}

Ucapan terimakasih kepada Deputi
Bidang Penguatan Riset dan
Pengembangan Kementrian Riset dan
Teknologi / Badan Riset Inovasi Nasional

(RISTEK-BRIN) Indonesia, Rektor Universitas Megarezky, Ketua LPPM Universitas Megarezky dan semua pihak yang telah berkontribusi dalam pelaksanaan penelitian ini yang tidak dapat dituliskan satu persatu.

\section{DAFTAR PUSTAKA}

Amalya, S., Bambang, S., Yulian, W., 2013. Efek Ekstrak Daun Pegagan (Centella Asiatica) Dalam Mempercepat Penyembuhan Luka Terkontaminasi Pada Tikus Putih (Rattus Novergicus) Galur Wistar. Universitas Brawijaya: Malang.

Ayu, P. 2012. Pengaruh Daun Sirih Merah Piper Betle Var. rubrum Terhadap Waktu Kesembuhan Luka Insisi Yang Diinfeksi Staphylococcus aureus Pada Tikus Putih. Surabaya: Universitas Airlangga.

Fitri, I., dan Widiyawati. 2017. Efektivitas Antibakteri Ekstrak Herba Meniran (Phylanthus niruri L.) Terhadap Pertumbuhan Bakteri Salmonella sp. dan propionibacterium acnes. Institut IImu Kesehatan Bhakti Wiyata: Kediri.

Hamzah, H., Fatimawali, Paulina, V., Y., Y., dan Jeane., M., 2013. Formulasi Salep Etanol Daun Nangka (Artocarpus heterophyllus L.) Dan Uji Efektivitas Terhadap Penyembuhan Luka Terbuka Pada Kelinci. FMIPA UNSRAT: Manado.

Irma, A. Puspita, ,S. Kp, RN, WOC (ET). 2013. Konsep Dasar Manajemen Keperawatan Luka. Penerbit Buku Kedokteran EGC: Jakarta. (Hal. $1,2,3,4,5,6,7,8,9,10,29,30,33,36-$ $55)$.

Kardinan, A., Fauzi R., K., 2004. Meniran Penambah Daya Tahan Tubuh Alami. PT. Agro Median Pustaka: Jakarta. (hal. 7 ).

Masruroh, E., Tukiran, Suyanto, dan Nurul, H., 2014. Analisis Awal Fitokimia Pada Tanaman Meniran (Phyllanthus niruri L.). Universitas Negeri Surabaya: Surabaya.

Murti, R. W., Nabila, A. P., Hanuriza, U. H., Ratna, K. Fahmi, N. Rina, W. 2016. Aktivitas Antioksidan dan Uji Iritasi sediaan Masker Gell pell - Off ekstrak Metanol Kulit Buah Rambutan (Nephelium lappaceum 
L.). Mahasiswa prodi farmasi fakultas kedokteran dan dosen prodi farmasi fakultas kedokteran Uniiversitas Islam Sultan Agung : Semarang.

Murlistyarini, S., Pengelupasan Kulit Secara Kimiawi, Penerbit UB Press, Malang.

Murti, R. W., Nabila, A. P., Hanuriza, U. H., Ratna, K. Fahmi, N. Rina, W. 2016. Aktivitas Antioksidan dan Uji Iritasi sediaan Masker Gell pell - Off ekstrak Metanol Kulit Buah Rambutan (Nephelium lappaceum L.). Mahasiswa prodi farmasi fakultas kedokteran dan dosen prodi farmasi fakultas kedokteran Uniiversitas Islam Sultan Agung : Semarang.

Murlistyarini, S., Pengelupasan Kulit Secara Kimiawi, Penerbit UB Press, Malang.

Nugrahani, S., Santika. 2013. Analisis Perbandingan Efektifitas Ekstrak Akar, Batang, Dan Daun Herba Meniran Dalam Menurunkan Kadar Glukosa Darah Mencit. Universitas Negeri Semarang:Indonesia.

Sari N, R, dan Setyowati E., 2014. Pengaruh Masker Jagung dan Minyak Zaitun Terhadap Perawatan Kulit wajah. Jurusan pendidikan kesejahteraan keluarga, fakultas teknik universitas negeri semarang : Semarang, Indonesia.

Partic, L., 2014. Perisai Segala Penyakit. Penerbit, PT Elex Media Komputindo Kelompok Gramedia, Jakarta.

Praseno, Titik, N., Muchammad, M., 2011. Perbandingan Efikasi Infusa Meniran (Phyllanthus niruri L.) dan Kotrimoksazol Pada Pengobatan Infeksi Kulit Oleh Staphylococcus aureus.Universitas Gadjah Mada: Yogyakarta.

Ruauw, Frans, E., W., Dan Michael, A., L., 2016. Pengaruh Lidah Buaya (Aloe vera) Terhadap Waktu Penutupan Luka Sayat Pada Mukosa Rongga Mulut Tikus Wistar.Universitas San Ratulangi:Manado.

Rohmatin, R., C., 2010. Presentase Karkas Dan Organ Dalam Kelinci Jantan Lokal yang Diberi Ransum Komplit
,Engandung Bungkil Inti Sawit Dengan Kombinasi Hijauan Berbeda. Fakultas Peternakan Institut Pertanian: Bogor.

Sari N, R, dan Setyowati E., 2014. Pengaruh Masker Jagung dan Minyak Zaitun Terhadap Perawatan Kulit wajah. Jurusan pendidikan kesejahteraan keluarga, fakultas tekhnik universitas negeri semarang : Semarang, Indonesia.

Santosa, Tri, D., 2008. Efektifitas Gentamisin Anestesi Dan lodine Povidone 10 $\%$ Terhadap Penyembuhan Luka Post Operasi Sectio Caesarea Di Rsud Purbalingga. Universitas Jenderal Soedirman: Purwokerto.

Sangadji, S., Adeane, C., Wullur, dan Widdhi, B., 2018. Formulasi Dan Uji Gel Ekstrak Etanol Herba Suruhan (Peperomia Pellucida L.) Terhadap Luka Bakar Pada Kelinci (Orygtolagus cuniculus). FMIPA UNSRAT: Manado.

Sewta, C., A., Christi, M., dan Jane, W., 2015. Uji Efek Daun Lidah Buaya (Aloe vera L) Terhadap Penyembuhan Luka Insisi Kulit Kelinci (Orytolagus cuniculus). Universitas Sam Ratulangi: Manado.

Shu, M., 2013. Formulasi Sediaan Gel Hand Sanitizer Dengan Bahan Aktif Triklosan $0,5 \%$, dan $1 \%$.Universitas Surabaya:Surabaya.

Ulviani, F., Yusriadi, Khilda, K., 2016. Pengaruh Gel Daun Sirih Merah (Piper cracatum Ruiz \& Pav) Terhadap Penyembuhan Luka Bakar Pada Kelinci (Orytolagus Cuniculus).Universitas Tandulako: Palu.

Yenti, Revi, Ria. A.,Linda, A. 2012. Formulasi Krim Ekstrak Etanol Daun kirinyuh (Euphaterium odoratum L.) Untuk Penyembuhan Luka. Majalah Kesehatan Pharm Medika, Vol.3 No.1 hal.227.

Wyatt, Jonatan. 2011. Forensic Medicine. New York: Oxford University Press.

Willey, John. 2013. Wound Healing and Skin Integrity.UK University of Hertfordshire. 


\section{Lampiran}

Tabel 1. Pembuatan Gel dan Formulasi Sediaan Gel

\begin{tabular}{llccc}
\hline \multirow{2}{*}{ Bahan } & \multirow{2}{*}{ Kegunaan } & \multicolumn{3}{c}{ Konsentrasi Bahan (\%) } \\
\cline { 2 - 5 } & FI & \multicolumn{1}{l}{ FII } & FIII \\
\hline Ekstrak etanol daun meniran & Zat aktif & 3 & 6 & 9 \\
HPMC & Basis Gel & 2 & 2 & 2 \\
Trietanolamin & Humektan & 10 & 10 & 10 \\
Gliserin & Emolien & 10 & 10 & 10 \\
Natrium Benzoat & Pengawet & 0,5 & 0,5 & 0,5 \\
Air suling & Pelarut & $100 \mathrm{ml}$ & 100 & 100 \\
\hline
\end{tabular}

